\title{
Public opinion on connected and automated vehicles: the Czech context
}

\author{
Vít Gabrhel ${ }^{a}$, Stanislav Ježek ${ }^{b}$, Darina Havlíčkováa \\ aTransport Research Centre, Lisenská 33a, Brno, 63600, Czech Republic \\ ${ }^{b}$ Department of Psychology, Faculty of Social Studies, Masaryk University, Joštova 10, Brno 60200 Czech Republic
}

ABSTRACT: Despite limited experience with Connected and automated vehicles (CAVs), the general public has been developing beliefs and attitudes about them. These expected benefits, concerns, trust, and other psychological factors play an important role in the way of accepting and adopting this new technology and as such should be available to various stakeholders. This study surveys the Czech public perceptions and attitudes relevant to policy-making in the area of CAVs. Between November 2017 and January 2018, a representative survey was conducted among the general population in the Czech Republic. Overall, 1065 randomly selected persons aged above 15 were personally interviewed. The sample, there were 523 (49\%) women; the average age was 50 years $(S D=17)$. Results showed that more than $65 \%$ of participants (i.e. 693) heard about CAVs before the survey. At the same time, $87 \%$ of the respondents with previous knowledge of the topic (i.e. 586) declared only limited awareness regarding CAVs. When it comes to the general opinion on CAVs, almost $40 \%$ of the respondents stated "rather positive" or "very positive" view. Also, more than $50 \%$ of the respondents associated wide usage of CAVs with better traffic safety. The majority of those sharing the negative opinion was members of an older generation, achieved a lower educational level and having lower household income. When it comes to the policy recommendations, the first wave of implementation should focus on applications in the more structured and controlled environment such as airports or metro.

KEYWORDS: Connected and automated vehicles; autonomous vehicles; public opinion; acceptance; concerns

\section{INTRODUCTION}

Connected and automated vehicles (CAVs) are not a regular part of traffic yet. However, the mere possibility of CAVs being involved in road transport encourages interest as well as concern among the general public. Expected benefits, concerns, trust, and other psychological factors will play an important role in the way of accepting and adopting this new technology (Becker \& Axhausen, 2017). As a result, stakeholders from both public and private sector focus on perceptions and attitudes related CAVs among different populations - ranging from the general public (Hudson, Orviska, \& Hunady, 2019; Hulse, Xie, \& Galea, 2018; Liljamo, Liimatainen, \& Pöllänen, 2018; Zmud, Sener \& Wagner, 2016), through seniors (Casley, Jardim, \& Quartulli, 2013), to experts in transportation (Begg, 2014).

If it is not stated differently, by the term CAVs or self-driving vehicles, we mean the high level of automation. In other words, level four according to the classification of the Society of Automotive Engineers (SAE; Smith, 2013). To be more specific, level four is when the automated driving system controls all aspects of the dynamic driving task (DDT), i.e. steering, braking, or accelerating. However, the level four allows action from the human operator at some circumstances, such as DDT performance-relevant system failure affecting perception module of a vehicle (Emzivat, Ibanez-Guzman, Martinet, \& Roux, 2017). Table 1 provides more information on the levels of automation.

So, despite the limited presence of CAVs on roads and in public spaces in general, opinion polls serve as a useful source of information for official authorities in policy-making. For example, answers in opinion polls may be relevant in identifying suitable media channels for disseminating information on CAVs (Nieuwenhuijsen Bastiaanssen Sersli, Waygood, 
Table 1. SAE levels of driving automation

\begin{tabular}{|c|c|c|c|c|c|}
\hline Level & Name & $\begin{array}{l}\text { Execution of steering } \\
\text { and acceleration/ } \\
\text { deceleration }\end{array}$ & $\begin{array}{l}\text { Monitoring } \\
\text { of driving } \\
\text { environment }\end{array}$ & $\begin{array}{l}\text { Fallback performance } \\
\text { of a dynamic driving } \\
\text { task }\end{array}$ & $\begin{array}{l}\text { System capability } \\
\text { (driving modes) }\end{array}$ \\
\hline 0 & No Driving Automation & Human & Human & Human & None \\
\hline 1 & Driver Assistance & Human and system & Human & Human & Some driving modes \\
\hline 2 & Partial Driving Automation & System & Human & Human & Some driving modes \\
\hline 3 & $\begin{array}{l}\text { Conditional Driving } \\
\text { Automation }\end{array}$ & System & System & Human & Some driving modes \\
\hline 4 & High Driving Automation & System & System & System & Most driving modes \\
\hline 5 & Full Driving Automation & System & System & System & All driving modes \\
\hline
\end{tabular}

Note: Level 0 automation refers to conventional vehicles, while level 5 refers to a fully autonomous vehicle that would require no human interventions.

\& Khreis, 2019). On the other hand, profit-oriented companies such as car manufacturers or mobility as a service (MaaS) providers may benefit from studies on respondent's willingness to switch to CAVs (Martin \& Shaneen, 2016).

Thus, researchers have asked various individuals if they have come across the topic of CAVs (e.g. Zmud, Sener, \& Wagner, 2016), what do they think about CAVs, whether they expect that wide use of CAVs would come with benefits such as fewer traffic congestions, whether they are afraid of the possibility of CAVs being hacked, or whether they could imagine driving a CAV in areas with dedicated lanes such as airport or hospital (Schoettle \& Sivak, 2014), among many other topics.

However, although numerous studies have tried to address various aspects of CAVs from the point of view of their potential users, most of these studies collected data on online samples (Gkartzonikas \& Gkritza, 2019; Hulse, Xie, \& Galea, 2018). This approach to sampling is susceptible to bias at least from two perspectives - the first concerns motivation to participate in web-based surveys specific from a general population. Web-based surveys usually yield lower response rate than other methods of selection (Asire, 2017). For example, it is easier to refuse participation in web-based surveys than in a telephone interview (Fricker, 2005). Respondents of online surveys are usually volunteers or members of an online panel. Both groups exercise motivation as a source of nonrandom nonresponse. For volunteers, it may be personal interest in some topic. For members of an online panel, it is the monetary substitution for their time. Also, there is an issue of coverage. Not every member of a population may be reachable through web-based surveys. Furthermore, it may be impossible to create a list of all members within the respective population to sample from (Bethlehem, 2010). Consequently, findings made on online samples of respondents may systematically differ in the area of interest from their respective populations.

Moreover, there is an uncovered space of knowledge related to the public opinion on CAVs in some parts of the world, such as in the Czech Republic. It is in spite the fact that the travel behaviour of the public in the Czech Republic, a member of the former Eastern Bloc, now a member of the European Union, differs from many Western countries. As an example, there is a higher share of public transportation in the modal split in the Czech Republic (Šimeček, Gabrhel, Tögel, \& Lazor, 2018). Different travel behaviour patterns may relate to different ways of using CAVs. Namely, frequent users of public transport may be more willing to travel with public transportation in an automated and connected form (Slowik \& Kamaké, 2017). Thus, this study aims to extend the scope of knowledge in the area of connected and automated driving, especially in terms of different scenarios of using CAVs. This paper provides an interpretation of the results in the international context to facilitate this effort.

Also, there is a plan to implement the technology of connected and automated driving in the Czech Republic in the near future (KPMG, 2019). Should it be implemented successfully, stakeholders must take into account expectations and concerns of the potential users, i.e. the general population. Consequently, there is a need for the representative data related to 
these perceptions and attitudes related to CAVs to achieve successful implementation. Thus, this study aims to provide insights relevant to the purposes of policy-making in the area of CAVs.

In summary, this paper describes general exposure and attitudes related to CAVs among the Czech public. More specifically, this paper focuses on the perceived benefits as well as concerns and the acceptability of various scenarios of CAVs usage.

\section{METHODS}

\subsection{Sampling and design}

Between November 2017 and January 2018, a survey on perceptions and attitudes related to CAVs among the general population in the Czech Republic was conducted. Overall, 59 professional interviewers personally interviewed 1065 persons older than 15 years via computer (CAPI). Respondents were selected through the multistage probabilistic sampling procedure, based on the list of address points in the Czech Republic.

Table 2 provides more detailed information regarding the socio-demography of the participants in the main study.
In the first step, there were 74 municipalities randomly sampled throughout the Czech Republic. Each of the sampling points contained at least ten primary households and 30 replacements. If there were more households per one sampling point sampled (e.g. in a panel house), in the second step, the desired number of households was randomly sampled from the list of households at the sampling point. Finally, within each of the selected households, one person older than 15 years was randomly sampled to participate in the survey.

Approximately one week before the scheduled time of the interview, selected households received a letter informing about the content of the survey as well as about the data privacy. Moreover, the letter contained information on the day and hour when the interview should take place as well as the contact information on the interviewer.

When it was not possible to contact a household at the first attempt, interviewers attempted to contact the household two more times within several days between each attempt. If it was not possible to contact the primary household during these three attempts, interviewers then moved to one of the three randomly selected replacement households.

Table 2 - Socio-demography of the sample.

\begin{tabular}{lll}
\hline Variables & Category & Sample $(\mathrm{n}=1065)$ \\
\hline Gender & Men & $542(51 \%)$ \\
Age (in years) & Women & $523(49 \%)$ \\
& M (SD) & $50(17)$ \\
Achieved level of education & Median & 51 \\
& Primge & $16-92$ \\
& Vocational & $72(7 \%)$ \\
Economic activity & High school & $377(35 \%)$ \\
Household gross monthly income* & College & $434(41 \%)$ \\
& Economically active & $182(17 \%)$ \\
& Economically inactive & $760(71 \%)$ \\
& Less than 361 EUR & $305(29 \%)$ \\
& $361-590$ EUR & $22(2 \%)$ \\
& $591-865$ EUR & $132(12 \%)$ \\
& $866-1180$ EUR & $193(18 \%)$ \\
& $1181-1966$ EUR & $311(29 \%)$ \\
& More than 1967 EUR & $324(30 \%)$ \\
\hline
\end{tabular}

*For a reference, the monthly average gross income for individuals was 29504 CZK or circa 1180 EUR (CSO, 2018). 
The design of the study, sampling procedure, and questionnaire were piloted on 54 individuals in October 2018. The pilot study was implemented the same way as was described in the preceding paragraphs.

\subsection{Questionnaire}

The questionnaire covered issues associated with CAVs and related topics such as attitudes towards new technology in general or respondents' travel behaviour. To facilitate comparability of the results, we adopted methods used in published research in this area (e.g. Cyganski, Fraedrich, \& Lenz, 2014; Sivak \& Schoettle, 2015; Schoettle \& Sivak, 2014; Schoettle \& Sivak, 2016; Zmud, Sener \& Wagner, 2016).

The interview began with a brief description of what is meant by CAVs in the context of this survey to standardise the intended meaning of CAVs among participants. The description was aligned with high driving automation (i.e. level four) defined by SAE (Smith, 2013). For the reasons of making the interview easier for respondents, we used the term "autonomous vehicles" instead of "connected and automated vehicles". However, the description fitted the term "connected and automated vehicles".

First, respondents were asked "Have you ever heard about CAVs before participating in this survey?" along with response options "Yes", "No" and "I don't know". Respondents were then asked about their general attitude towards CAVs: "What is your general opinion regarding CAVs? Even if you had never heard of CAVs before participating in this survey, please give us your opinion based on the description you just read." with response options "Very negative", "Rather negative", "Neither negative nor positive", "Rather positive", and "Very positive".

Respondents were also asked whether they could "Imagine self-driving cars were on the market now either for purchase or rental. What is the likelihood that you would ride in a self-driving car for everyday use?" along with following response options "Very unlikely", "Rather unlikely", "Rather likely", "Very likely".

A set of items focused on the perceived benefits (e.g. "Improved safety for pedestrians") related to wide usage of CAVs ("How likely do you think it is that the following benefits will occur when using CAVs?). Respondents indicated on a four-point Likert scale how likely they think CAVs would bring a benefit in question. Those who chose "Very unlikely" or "Some- what unlikely" were asked for the main reason why they would not use CAVs with the following response options: "Legal issues", "Price", "Safety concerns", and "Lack of trust in this technology. Also, they had an opportunity to state a different reason through an open-ended answer.

Respondents were further asked whether their current car or cars contain any elements of advanced driver-assistance systems (ADAS) such as automatic parking, adaptive cruise control or lane centring. In this context, the term automated driving does not mean automated driving in its entirety. It refers to elements of automated driving, represented by various ADAS features. These, despite not reaching the degree of automated driving, which is expected to manifest in highly automated vehicles, provide an experience with automating one or more driving tasks. Consequently, this (in)familiarity may be a predictor of attitude towards a more advanced technology from the same area (Meschtscherjakov et al., 2015). The item offered response options "Yes" and "No".

In their answers, the Czech respondents were also asked to express their concerns ("How concerned are you about the following issues related to CAVs?") related to specific aspects of using CAVs (e.g. "Data privacy"). The response scale was "Not at all concerned", "Slightly concerned", "Moderately concerned", and "Very concerned".

In addition to the perceived benefits and concerns related to self-driving vehicles, interviewers possible scenarios presented to respondents in which the respondents could come into contact with self-driving vehicles (e.g. "Self-driving taxis"). These scenarios included connected and automated cars as well as other self-driving vehicles such as self-driving trucks or trams. The item itself again focused on the concerns regarding these scenarios: "How concerned are you about the following possible scenarios with CAVs?". The response scale for each scenario was "Not at all concerned", "Slightly concerned", "Moderately concerned", and "Very concerned".

\subsection{Analyses}

The data were analysed via statistical package $\mathrm{R}$ (version 3.5.1.; R Core Team, 2018) and imported to $\mathrm{R}$ via the readxl package (version 1.2.0; Wickham \& Bryan, 2018). The dplyr package (version 0.7.8; Wickham, François, Henry, \& Müller, 2018) was used for data wrangling. The psych package (version 
1.8.12; Revelle, 2018) was used to calculate descriptive statistics. The ggplot2 (version 3.1.0.; Wickham, 2016) and ggthemes (version 4.1.0; Arnold, 2019) packages provided with graphs.

Analyses of the perceived benefits of and concerns about the widespread use of CAVs followed a two-step approach. First, descriptive statistics are presented, and then bivariate analyses build upon the descriptive statistics. Bivariate analyses aim to provide additional information on the associations between perceived concerns and benefits investigating whether there are any patterns in the respondents' thinking about the topic.

\section{RESULTS}

More than $65 \%$ of participants $(n=693)$ had heard about CAVs vehicles before the survey was conducted. At the same time, $88 \%$ of those respondents with previous knowledge of the topic $(n=617)$ declared only limited knowledge regarding CAVs vehicles.

When it comes to the general opinion on CAVs vehicles, almost $40 \%$ of the respondents reported the "rather positive" or "very positive" view $(n=406)$. Further, $40 \%$ found themselves in the middle ground: "neither positive nor negative" $(n=418)$. Consequently, approximately $20 \%$ of participants had a negative opinion on CAVs vehicles $(n=241)$. Respondents reporting no previous knowledge of the topic tend to see CAVs vehicles slightly more negatively than those who reported knowledge about the issue $\left(\chi^{2}(4)=\right.$ $17.93, \mathrm{p}=.001$, Cramér's V $=.13$, “I don't know” responses not included in the analysis).

When asked how probable it is that they would use an automated vehicle for their everyday mobility, around $60 \%$ of respondents saw this as something unlikely. On the other hand, almost $30 \%$ of participants reported that their current car(s) already contain at least one element of automation technology, e.g. cruise control. Also, respondents who owned a vehicle with ADAS reported they would likely use CAVs in their everyday mobility more often than their counterparts $\left(\chi^{2}(3)=9.73\right.$, $\mathrm{p}=.02, \mathrm{~V}=.10)$.

Respondents who stated that they would not use self-driving vehicles for their everyday mobility were asked to indicate the main reason for their decision. The most frequent answer was the expected price of self-driving cars (231 participants, i.e. 34\%) followed by a lack of trust in the technology (168, i.e. $28 \%)$. Another 140 participants (21\%) reported safety concerns. Only 32 respondents (5\%) would not use selfdriving vehicles due to legal issues.

When it comes to the expected benefits of CAVs, more than $50 \%$ of respondents associate wide usage of CAVs with better traffic safety or more effective car economy. The former manifests in expected fewer car accidents ( $63 \%$ of respondents chose either "Somewhat likely" or "Very likely") or their reduced severity ( $63 \%$ of respondents), but also in improved emergency response to car crashes (62\% of respondents) or in expected improvement of traffic safety for pedestrians (66\% of respondents) and cyclists (66\% of respondents). The latter relates to better fuel economy (75\% of respondents) or lower vehicle emissions (70\%). Interestingly, respondents do not expect lower insurance rates as a result of introducing CAVs (61\% of respondents choose either "Somewhat unlikely" or "Very unlikely").

At the same time, half or more of the participants did not expect improvements in the transportation system, either in terms of shorter travel time (63\% of respondents choose either "Somewhat unlikely" or "Very unlikely") or fewer traffic congestions ( $63 \%$ of respondents"). When speaking about transportation system, on the other hand, more than half of the participants thought that wide usage of self-driving cars would increase the accessibility of places that are out of reach of public transportation (67\% of respondents choose either "Somewhat likely" or "Very likely"). Table 3 brings a more elaborated view on the issue.

If we focus on the relationship between individual items in this section, we can see the to between items concerning traffic safety as such ("Fewer crashes" and "Reduced severity of crashes", $r_{s}=.74$ ) or traffic safety for vulnerable mobility system users (pedestrians and cyclists, $r_{s}=.83$ ). Expectations of possible benefits from introducing CAVs were also related in terms of improving the traffic flow ("Fewer traffic congestions" or "Shorter travel time", $\mathrm{r}_{\mathrm{s}}=.64$ ) or vehicle functioning ("Lower vehicle emissions" and "Better fuel economy", $\mathrm{r}_{\mathrm{s}}=.61$ ). Table 4 summarises the substantive similarity in the way that respondents answered these items.

As for the concerns related to CAVs, respondents in the sample declared none or only minimum concerns in learning to use self-driving cars (59\%) or minimum concerns that self-driving vehicles would not drive as well as human drivers (53\%). 
More than the half of the respondents were moderately or very concerned regarding situations difficult to anticipate for CAVs (56\%), safety consequences of equipment or system failures (66\%), interacting with non-self-driving vehicles (58\%) or self-driving vehicles confused by unexpected situations (60\%). There are more detailed descriptive statistics in Table 5.

Table 3. How likely do you think it is that the following benefits will occur when using self-driving vehicles? Two of the most frequent categories of the answer are highlighted in each row.

\begin{tabular}{|c|c|c|c|c|c|c|c|c|}
\hline \multirow[t]{2}{*}{ Benefit } & \multicolumn{2}{|c|}{ Very unlikely } & \multicolumn{2}{|c|}{$\begin{array}{l}\text { Somewhat } \\
\text { unlikely }\end{array}$} & \multicolumn{2}{|c|}{$\begin{array}{l}\text { Somewhat } \\
\text { likely }\end{array}$} & \multicolumn{2}{|c|}{ Very likely } \\
\hline & $\mathrm{N}$ & $\%$ & $\mathrm{~N}$ & $\%$ & $\mathrm{~N}$ & $\%$ & $\mathrm{~N}$ & $\%$ \\
\hline Fewer crashes & 104 & 9.9 & 278 & 26.4 & 520 & 49.5 & 149 & 14.2 \\
\hline Reduced severity of crashes & 102 & 9.7 & 297 & 28.2 & 499 & 47.3 & 156 & 14.8 \\
\hline Improved emergency response to crashes & 87 & 8.3 & 262 & 25.1 & 458 & 43.9 & 237 & 22.7 \\
\hline Fewer traffic congestions & 164 & 15.5 & 374 & 35.4 & 386 & 36.5 & 133 & 12.6 \\
\hline Shorter travel time & 136 & 12.9 & 389 & 37 & 395 & 37.6 & 131 & 12.5 \\
\hline Lower vehicle emissions & 88 & 8.4 & 215 & 20.5 & 485 & 46.2 & 262 & 24 \\
\hline Better fuel economy & 60 & 5.8 & 196 & 18.8 & 518 & 49.7 & 268 & 25.7 \\
\hline Lower insurance rates & 279 & 26.7 & 355 & 33.9 & 311 & 29.7 & 102 & 9.7 \\
\hline Improved safety for pedestrians & 102 & 9.8 & 249 & 23.8 & 463 & 44.2 & 232 & 22.2 \\
\hline Improved safety for cyclists & 104 & 9.9 & 249 & 23.7 & 473 & 45.1 & 223 & 21.3 \\
\hline $\begin{array}{l}\text { Better accessibility of places out of reach of public } \\
\text { transportation }\end{array}$ & 112 & 10.7 & 240 & 22.8 & 506 & 48.1 & 194 & 18.4 \\
\hline
\end{tabular}

$\mathrm{N}=1065$

Table 4. Correlation matrix of expected benefits of CAVs (in Spearman's rho).

\begin{tabular}{|c|c|c|c|c|c|c|c|c|c|c|c|}
\hline Benefit & 1) & 2) & 3) & 4) & 5) & 6) & 7) & 8) & 9) & 10) & 11) \\
\hline 1) Fewer crashes & 1 & & & & & & & & & & \\
\hline 2) Reduced severity of crashes & $0.74 *$ & 1 & & & & & & & & & \\
\hline $\begin{array}{l}\text { 3) Improved emergency } \\
\text { response to crashes }\end{array}$ & $0.45^{*}$ & $0.49 *$ & 1 & & & & & & & & \\
\hline 4) Fewer traffic congestions & $0.47^{*}$ & $0.46^{*}$ & $0.41^{*}$ & 1 & & & & & & & \\
\hline 5) Shorter travel time & $0.43^{*}$ & $0.42 *$ & $0.35 *$ & $0.63 *$ & 1 & & & & & & \\
\hline 6) Lower vehicle emissions & $0.3^{*}$ & $0.31^{*}$ & $0.37^{*}$ & $0.37 *$ & $0.39 *$ & 1 & & & & & \\
\hline 7) Better fuel economy & $0.36^{*}$ & $0.34 *$ & $0.37 *$ & $0.33 *$ & $0.35^{*}$ & $0.61 *$ & 1 & & & & \\
\hline 8) Lower insurance rates & $0.28 *$ & $0.27 *$ & $0.16^{*}$ & $0.33^{*}$ & $0.32 *$ & $0.20 *$ & $0.3 *$ & 1 & & & \\
\hline $\begin{array}{l}\text { 9) Improved safety for } \\
\text { pedestrians }\end{array}$ & $0.50 *$ & $0.52 *$ & $0.40 *$ & $0.37^{*}$ & $0.36^{*}$ & $0.36^{*}$ & $0.41^{*}$ & $0.32 *$ & 1 & & \\
\hline 10) Improved safety for cyclists & $0.51^{*}$ & $0.52 *$ & $0.40 *$ & $0.38 *$ & $0.35^{*}$ & $0.35^{*}$ & $0.42 *$ & $0.32 *$ & $0.83 *$ & 1 & \\
\hline $\begin{array}{l}\text { 11) Better accessibility of } \\
\text { places out of reach of public } \\
\text { transportation }\end{array}$ & $0.38 *$ & $0.36^{*}$ & $0.36^{*}$ & $0.36^{*}$ & $0.38 *$ & $0.38 *$ & $0.42 *$ & $0.30 *$ & $0.45^{*}$ & $0.47^{*}$ & 1 \\
\hline
\end{tabular}

$\mathrm{N}=1065 ;{ }^{*} \mathrm{p}<.05$ 
Table 5. How concerned are you about the following issues related to completely self-driving vehicles? Two of the most frequent categories of the answer are highlighted in each row.

\begin{tabular}{lcccccccc}
\hline Concern & \multicolumn{2}{c}{$\begin{array}{c}\text { Not at all } \\
\text { concerned }\end{array}$} & \multicolumn{2}{c}{$\begin{array}{c}\text { Slightly } \\
\text { concerned }\end{array}$} & \multicolumn{2}{c}{$\begin{array}{c}\text { Moderately } \\
\text { concerned }\end{array}$} & \multicolumn{2}{c}{$\begin{array}{c}\text { Very } \\
\text { concerned }\end{array}$} \\
\cline { 2 - 10 } & $\mathrm{N}$ & $\%$ & $\mathrm{~N}$ & $\%$ & $\mathrm{~N}$ & $\%$ & $\mathrm{~N}$ & $\%$ \\
\hline Safety consequences of equipment/system failures & 114 & 10.8 & 248 & 23.6 & 497 & 47.2 & 194 & 18.4 \\
Data privacy & 227 & 21.6 & 305 & 29.1 & 377 & 35.9 & 140 & 13.4 \\
Interacting with non-self-driving vehicles & 140 & 13.2 & 303 & 28.7 & 441 & 41.7 & 173 & 16.4 \\
Learning to use self-driving vehicles & 269 & 25.5 & 357 & 33.9 & 320 & 30.3 & 109 & 10.3 \\
System performance in poor weather & 198 & 18.9 & 331 & 31.6 & 393 & 37.6 & 125 & 11.9 \\
Self-driving vehicles confused by unexpected situations & 12 & 11.4 & 305 & 29 & 419 & 39.9 & 206 & 19.6 \\
Self-driving vehicles not driving as well as human drivers & 218 & 20.7 & 340 & 32.2 & 367 & 34.8 & 130 & 12.3 \\
Self-driving vehicles driving worse than me as a driver & 292 & 27.7 & 340 & 32.2 & 316 & 30 & 107 & 10.1 \\
Self-driving vehicles not behaving the way I would need & 185 & 17.5 & 344 & 32.6 & 365 & 34.6 & 162 & 15.3 \\
\hline
\end{tabular}

$\mathrm{N}=1065$

Table 6. Correlation matrix of concerns related to CAVs (in Spearman's rho).

\begin{tabular}{|c|c|c|c|c|c|c|c|c|c|}
\hline Concern & 1) & 2) & 3) & 4) & 5) & 6) & 7) & 8) & 9) \\
\hline $\begin{array}{l}\text { 1) Safety consequences of equipment/system } \\
\text { failure }\end{array}$ & 1 & & & & & & & & \\
\hline 2) Data privacy & $0.42^{*}$ & 1 & & & & & & & \\
\hline 3) Interacting with non-self-driving vehicles & $0.4^{*}$ & $0.44^{*}$ & 1 & & & & & & \\
\hline 4) Learning to use self-driving vehicles & $0.22^{*}$ & $0.21^{*}$ & $0.27^{*}$ & 1 & & & & & \\
\hline 5) System performance in poor weather & $0.38^{*}$ & $0.34^{*}$ & $0.34^{*}$ & $0.52^{*}$ & 1 & & & & \\
\hline $\begin{array}{l}\text { 6) Self-driving vehicles confused by unexpected } \\
\text { situations }\end{array}$ & $0.47^{*}$ & $0.39^{*}$ & $0.4^{*}$ & $0.33^{*}$ & $0.54^{*}$ & 1 & & & \\
\hline $\begin{array}{l}\text { 7) Self-driving vehicles not driving as well as } \\
\text { human drivers }\end{array}$ & $0.38^{*}$ & $0.35^{*}$ & $0.34^{*}$ & $0.39^{*}$ & $0.53^{*}$ & $0.58^{*}$ & 1 & & \\
\hline $\begin{array}{l}\text { 8) Self-driving vehicles driving worse than me } \\
\text { as a driver }\end{array}$ & $0.31^{*}$ & $0.33^{*}$ & $0.28^{*}$ & $0.3^{*}$ & $0.4^{*}$ & $0.4^{*}$ & $0.61^{*}$ & 1 & \\
\hline $\begin{array}{l}\text { 9) Self-driving vehicles not behaving the way I } \\
\text { would need }\end{array}$ & $0.33^{*}$ & $0.3^{*}$ & $0.28^{*}$ & $0.32^{*}$ & $0.43^{*}$ & $0.52^{*}$ & $0.53^{*}$ & $0.56^{*}$ & 1 \\
\hline
\end{tabular}

$\mathrm{N}=1065 ;{ }^{*} \mathrm{p}<.05$

As with the perceived benefits, respondents showed patterns in their answers regarding perceived concerns related to CAVs. One such pattern within variables could be perceived as the general concern regarding CAVs performance, either in comparison to human drivers ("Self-driving vehicle not driving as well as human drivers" and "Selfdriving vehicles driving worse than me as a driver", $\left.r_{s}=.61\right)$ or the safety of CAVs in a more broad sense ("Safety consequences of equipment/system fail- ure, $r_{s}=.42$ ). Table 6 summarises a substantive similarity in the way that respondents answered these items.

When it comes to driving a self-driving car within areas such as an airport, two-thirds of the participants would be concerned slightly or not concerned at all. Also, $70 \%$ of participants were not (or to a very limited degree) concerned with autonomous metro or subway. On the other hand, more than half of the participants were moderately or very concerned with 
self-driving trucks and buses. For detailed descriptive statistics see Table 7 .

Strong associations were also found in the respondents' concerns related to specific use cases for CAVs. For example, the more were respondents concerned with the idea of self-driving buses, the more they were concerned with the idea of self-driving heavy trucks $\left(\mathrm{r}_{\mathrm{s}}=.79\right)$. Also, respondents who were not concerned by the idea of self-driving metro declared only limited concerns regarding self-driving trams. Table 8 summarises the relationship between the perceptions of individual scenarios.

\section{DISCUSSION}

This study aimed to capture the public opinions, beliefs and attitudes related to connected and auto- mated vehicles in the Czech Republic using a representative sample. Over $65 \%$ of Czechs in this study had heard about CAVs before the survey was conducted. This percentage is similar to countries like Great Britain, Australia or the USA (Schoettle \& Sivak, 2014). The CAVs as a topic are thus present in the public discourse to the same degree in the Czech Republic as in Western countries. However, the mere recognition of the issue does not provide us with information about the level of the public knowledge of the topic. Neither does it provide us with information about the channels through which Czechs learn about CAVs. Both knowledge of the topic and the channels through which information on CAVs reaches members of the general public is important for policymakers to facilitate the debate and promote objective information on the topic of CAVs.

Table 7. How concerned are you about the following possible scenarios with completely self-driving vehicles? Two of the most frequent categories of the answer are highlighted in each row.

\begin{tabular}{lcccccccc}
\hline Scenario & \multicolumn{2}{c}{$\begin{array}{c}\text { Not at all } \\
\text { concerned }\end{array}$} & \multicolumn{2}{c}{$\begin{array}{c}\text { Slightly } \\
\text { concerned }\end{array}$} & \multicolumn{2}{c}{$\begin{array}{c}\text { Moderately } \\
\text { concerned }\end{array}$} & \multicolumn{2}{c}{$\begin{array}{c}\text { Very } \\
\text { concerned }\end{array}$} \\
\cline { 2 - 10 } & $\mathrm{N}$ & $\%$ & $\mathrm{~N}$ & $\%$ & $\mathrm{~N}$ & $\%$ & $\mathrm{~N}$ & $\%$ \\
\hline $\begin{array}{l}\text { Self-driving vehicles moving from one location to } \\
\text { another while unoccupied }\end{array}$ & 185 & 17.5 & 344 & 32.6 & 365 & 34.6 & 162 & 15.3 \\
Self-driving commercial vehicles such as heavy trucks & 157 & 15.1 & 261 & 25.1 & 324 & 31.1 & 299 & 28.7 \\
Self-driving buses & 149 & 14.3 & 303 & 29.1 & 319 & 30.6 & 271 & 26 \\
Taxis that are completely self-driving & 243 & 23.3 & 330 & 31.7 & 309 & 29.7 & 159 & 15.3 \\
Driving a self-driving vehicle in areas such as airports & 440 & 41.8 & 344 & 32.6 & 196 & 18.6 & 74 & 7 \\
Self-driving metro/subway & 422 & 39.8 & 315 & 29.7 & 220 & 20.7 & 104 & 9.8 \\
Self-driving tram & 306 & 29.2 & 309 & 29.5 & 294 & 28 & 140 & 13.3 \\
\hline
\end{tabular}

$\mathrm{N}=1065$

Table 8. Correlation matrix of scenarios of CAVs (in Spearman's rho).

\begin{tabular}{|c|c|c|c|c|c|c|c|}
\hline Scenario & 1) & 2) & 3) & 4) & 5) & 6) & 7) \\
\hline $\begin{array}{l}\text { 1) Self-driving vehicles moving from one location to } \\
\text { another while unoccupied }\end{array}$ & 1 & & & & & & \\
\hline 2) Self-driving commercial vehicles such as heavy trucks & $0.53^{*}$ & 1 & & & & & \\
\hline 3) Self-driving buses & $0.55^{*}$ & $0.79^{*}$ & 1 & & & & \\
\hline 4) Taxis that are completely self-driving & $0.57^{*}$ & $0.58^{*}$ & $0.68^{*}$ & 1 & & & \\
\hline 5) Driving a self-driving vehicle in areas such as airports & $0.41^{*}$ & $0.22 *$ & $0.29 *$ & $0.44^{*}$ & 1 & & \\
\hline 6) Self-driving metro/subway & $0.42^{*}$ & $0.24 *$ & $0.33^{*}$ & $0.42^{*}$ & $0.64 *$ & 1 & \\
\hline 7) Self-driving tram & $0.5^{*}$ & $0.39^{*}$ & $0.46^{*}$ & $0.5^{*}$ & $0.54^{*}$ & $0.76^{*}$ & 1 \\
\hline
\end{tabular}

$\mathrm{N}=1065 ;{ }^{*} \mathrm{p}<.05$ 
Willingness of Czechs to use self-driving cars does not seem to differ from countries such as Germany or the Netherlands. There, circa $40 \%$ of participants declared willingness to use self-driving cars for everyday mobility. For comparison - it was $85 \%$ of participants in India, $75 \%$ in China, and $36 \%$ in Japan (Lang et al., 2016). These differences could relate to the expected benefits of using CAVs in respective countries in comparison to the current vehicles. Different levels of willingness to use CAVs may also reflect respondents' evaluation of the current transportation system in their countries, especially regarding traffic congestion, car-crashes or emissions (Lang et al., 2016). Czechs may see the introduction of CAVs as incremental rather than substantial improvement in the transport. Regardless of the size of the improvements, Czechs still tend to anticipate an increase in - broadly speaking - traffic safety (especially for the vulnerable road users) and to a lesser extent in increased efficiency of vehicles (e.g. better fuel economy) and transport system (e.g. better traffic flow).

Previous experience with automation technology in transport is weakly associated with higher willingness to use CAVs in everyday mobility. The source of the association is not clear, however. The wording of the question ("Does your current car contain automation technology?") did not necessarily cover those respondents with automation technology in their previous cars or those who had travelled with a vehicle containing automation technology other than a car (e.g. train), but who did not have automation technology installed in their current vehicle when the survey was conducted. Moreover, even if someone has experience with automation technology, he or she may evaluate individual applications of automation technology differently. For example, $55 \%$ of respondents in this survey whose cars had been equipped with some automation technology declared at least some concerns over using an automated tram. In comparison, $62 \%$ of people with no such technology in their vehicles showed at least some concerns. However, concerning connected and automated trucks, both groups of respondents reported the same levels of concern.

The mere presence of automated technology in the current car (such as lane control) relates to the higher levels of subjective probability of using selfdriving vehicles for everyday mobility. This outcome is in line with findings from international studies (e.g. Kyriakidis et al., 2015). However, the relation- ship between these two variables is weak, and the causality is not clear. Thus, mere exposure to some technology does not guarantee the satisfying experience and willingness to use more advanced technology from the same domain. Moreover, this study did not focus on other socio-economic aspects of willingness to use CAVs like preference for personal ownership versus car-sharing of CAVs (e.g. Becker \& Axhausen, 2017).

When it comes to concerns regarding CAVs, Czech participants differed from those from the USA, as the latter were more concerned with legal aspects of using CAVs or data privacy (Schoettle \& Sivak, 2014). Respondents in this survey frequently declared concerns regarding the performance of CAVs in difficult situations (e.g. poor weather) or in comparison to human drivers. At the same time, more than half of the respondents were not concerned that they would not be able to learn how to operate CAVs. This relative self-confidence, along with relative ease concerning the cybersecurity, may represent a weak point for future implementation of CAVs in the Czech Republic. For example, human operators may overestimate their capacities when taking-over control of their vehicles a few moments after they were doing something completely unrelated to driving.

As for the scenarios of the CAVs use, responses in the survey indicate that a more controlled environment in which CAVs would be used elicits fewer concerns. When it comes to driving a self-driving car within areas such as airports, two-thirds of the participants would be concerned slightly or not concerned at all and even more people are unconcerned (or concerned to a very small degree) with autonomous metro or subway. Since such systems as automated trains operate regularly around the world, a firsthand or overheard experience of someone else may contribute to the less perceived concerns. Moreover, respondents who used public transport for purposes of travelling to school or work during the past week reported the least concerns regarding using automated tram $-44 \%$. For comparison, it was $38 \%$ among those respondents who drove their cars in the same timeframe for the same purposes. This result corroborates previous findings that frequent users of public transport may be more willing to travel with public transportation in an automated and connected form (Slowik \& Kamaké, 2017).

Also, the Czech participants did not differ from those from Great Britain, the USA or Australia regarding concerns related to self-driving trucks or 
self-driving buses. On the other hand, the Czech respondents showed fewer concerns related to selfdriving taxi (Schoettle \& Sivak, 2014).

Concerning socio-demography, the majority of those sharing the negative opinion was, in comparison to those who held the positive opinion, members of an older generation, achieved a lower educational level and having lower household income. However, the proportion of men and women in the two groups was almost the same.

Based on the previously discussed results, when it comes to the policy recommendations, the first wave of implementation of CAVs should focus on applications in the more structured and controlled environment. Some of the stakeholders have already made the first steps in this direction. For example, Václav Havel Prague Airport aims to employ self-driving vehicles as the law approving such implementation is about to come into effect in the first half of 2019 (Václav Havel Airport Prague, 2019). Another instance of the introduction of CAVs to the public could be public transport, a mode of transportation that is frequently used in the Czech Republic and which also seems to raise a limited amount of concerns among representants of the general public. Last but not least, objective information delivered to the general audience is required to debunk myths and raise awareness. Such an approach is needed not just to increase confidence in CAVs as technology (one third to one-half of respondents showed concerns in one or more aspects of CAVs), but also to prevent specific issues related with the implementation of CAVs. For example, taking over a CAV represents one of the major challenges related to the introduction of CAVs, especially in level 3 of SAE (Smith, 2013; Wu et al., 2019). Cognitive and psychomotricity limits of the human operators should not be taken lightly, especially when less than half of the respondents were concerned with the idea of learning how to operate CAVs would be difficult for them.

Acknowledgements: This contribution was created with the financial support of the Ministry of Education, Youth and Sports as part of the National Sustainability Programme I, project of Transport R\&D Centre (LO1610) on the research infrastructure acquired from the Operational Programme Research and Development for Innovation (CZ.1.05/2.1.00/03.0064).

\section{REFERENCES}

Arnold, J. B. (2019, May 12). ggthemes: Extra Themes, Scales and Geoms for 'ggplot2'. Retrieved from: https://CRAN.R-project.org/package=ggthemes

Asire, A. M. (2017). a Meta-Analysis of the Effects of Incentives on Response Rate in Online Survey Studies. Electronic Theses and Dissertations. 1317. https://digitalcommons.du.edu/ etd/1317

Becker, F., \& Axhausen, K. W. (2017). Literature review on surveys investigating the acceptance of autonomous vehicles. Transportation, 44(6), 1293-1306. doi: 10.1007/s11116-0179808-9

Begg, D. (2014, August 14). a 2050 Vision for London: What are the Implications of Driverless Transport. Retrieved at: $\mathrm{http}: / /$ www.transporttimes.co.uk/Admin/uploads/64165-transporttimes_a-2050-vision-for-london_aw-web-ready.pdf

Bethlehem, J. (2010). Selection Bias in Web Surveys. International Statistical Review, 78 (2), pp. 161-168. doi: 10.1111/j.1751-5823.2010.00112.x

Casley, S., Jardim, A., \& Quartulli, A. (2013). a Study of Public Acceptance of Autonomous Cars. Bachelor of Science thesis. Worcester, MA: Worcester Polytechnic Institute.

Cyganski, R., Fraedrich, E., Lenz, B. (2014). Travel-time valuation for automated driving: a use-case driven study. Washington: TRB.

Czech Statistical Office. (2018, March 9). Average wages - 4th quarter of 2017. Retrieved from: https://www.czso.cz/csu/ czso/ari/average-wages-4-quarter-of-2017

Emzivat, Y., Ibanez-Guzman, J., Martinet, P., \& Roux, O. H. (2017). Dynamic driving task fallback for an automated driving system whose ability to monitor the driving environment has been compromised. 2017 IEEE Intelligent Vehicles Symposium (IV). doi: 10.1109/ivs.2017.7995973

Fricker, S., Galesic, M., Tourangeau, R., \& Yan, T. (2005). An experimental comparison of web and telephone surveys. Public Opinion Quarterly, 69, 370-392.

Gkartzonikas, C., \& Gkritza, K. (2017). What have we learned? a review of stated preference and choice studies on autonomous vehicles. Transportation Research Part C: Emerging Technologies, 98, 323-337. doi: 10.1016/j.trc.2018.12.003

Hudson, J., Orviska, M., \& Hunady, J. (2019). People's attitudes to autonomous vehicles. Transportation Research Part A: Policy and Practice, 121, 164-176. doi:10.1016/j.tra.2018.08.018

Hulse, L. M., Xie, H., \& Galea, E. R. (2018). Perceptions of autonomous vehicles: Relationships with road users, risk, gender and age. Safety Science,102, 1-13. doi:10.1016/j. ssci.2017.10.001

KPMG. (2019, 17 February). 2019 Autonomous Vehicles Readiness Index. Retrieved from: https://assets.kpmg/content/dam/ kpmg/xx/pdf/2019/02/2019-autonomous-vehicles-readinessindex.pdf

Kyriakidis, M., Happee, R., \&amp; Winter, J. C. F. De. (2015). Public opinion on automated driving: Results of an interna- 
tional questionnaire among 5000 respondents. Transportation Research Part F: Psychology and Behaviour, 32, 127-140. doi: 10.1016/j.trf.2015.04.014

Liljamo, T., Liimatainen, H., \& Pöllänen, M. (2018). Attitudes and concerns on automated vehicles. Transportation Research Part F: Traffic Psychology and Behaviour, 59, 24-44. doi:10.1016/j.trf.2018.08.010

Martin, E., \& Shaheen, S. (2016, July 12). Impacts of Car2go on vehicle ownership, modal shift, vehicle miles traveled, and greenhouse gas emissions: An analysis of five North American cities. Retrieved from http://innovativemobility.org/wp-content/uploads/2016/07/Impactsofcar2go_FiveCities_2016.pdf

Meschtscherjakov, A., Tscheligi, M., Szostak, D., Ratan, R., McCall, R., Politis, I., \& Krome, S. (2015). Experiencing Autonomous Vehicles. Proceedings of the 33rd Annual ACM Conference Extended Abstracts on Human Factors in Computing Systems CHI EA '15.doi:10.1145/2702613.2702661

Nieuwenhuijsen, M., Bastiaanssen, J., Sersli, S., Waygood, E. O. D., \& Khreis, H. (2018). Implementing Car-Free Cities: Rationale, Requirements, Barriers and Facilitators. In Integrating Human Health into Urban and Transport Planning (pp. 199-219). Springer International Publishing. doi: 10.1007/978-3-319-74983-9_11

R Core Team (2018, December 20). R: a language and environment for statistical computing. $\mathrm{R}$ Foundation for Statistical Computing. Retrieved from https://www.R-project.org/

Revelle, W. (2019, January 13). psych: Procedures for Personality and Psychological Research. Retrieved from https://cran.rproject.org/web/packages/psych/psych.pdf

Sivak, M. \& Schoettle, B. (2015). Road safety with self-driving vehicles: general limitations and road sharing with conventional vehicles. UMTRI 2015-2. University of Michigan, Transportation Research Institute. Ann Arbor, Michigan.

Schoettle, B., \& Sivak, M. (2014). a survey of public opinion about autonomous and self-driving vehicles in the U.S., the U.K., and Australia. Michigan: The University of Michigan Transportation Research Institute.

Schoettle, B. \& Sivak, M. (2016). Motorists' preferences for different levels of vehicle automation: 2016. UMTRI SWT-2016-8. University of Michigan, Transportation Research Institute. Ann Arbor, Michigan.

Slawik, P., \& Kamaté, F. (2017, July 27). New Mobility: Today's Technology and Policy Landscape. The International Council On Clean Transportation. Retrieved from https://www.theicct.org/ sites/default/files/publications/New-mobility-landscape_ICCT-white-paper_27072017_vF.pdf

Smith, B. W. (2013, December 18). SAE levels of driving automation. Retrieved from: http://cyberlaw.stanford.edu/ blog/2013/12/sae-levels-driving-automation

Šimeček, M., Gabrhel, V., Tögel, M., \& Lazor, M. (2018). Travel behaviour of seniors in Eastern Europe: a comparative study of Brno and Bratislava. European Transport Research Review, 10(1). doi: 10.1007/s12544-018-0286-8

Václav Havel Airport Prague. (2019, January 8). Prague Airport wants to be like Dubai. It will drive you around in a driverless car. Retrieved from: https://www.pragueairport.co.uk/pragueairport-wants-to-be-like-dubai-it-will-drive-you-around-in-adriverless-car/

Wickham, H., \& Bryan, J. (2018, December 19). readxl: Read Excel Files. Retrieved from https://CRAN.R-project.org/ package $=$ readxl

Wickham, H., François, R., Henry, L., \& Müller, K. (2018, November 10). dplyr: a Grammar of Data Manipulation. Retrieved from https://CRAN.R-project.org/package=dplyr

Wickham, H. (2016). ggplot2: Elegant Graphics for Data Analysis. New York: Springer-Verlag.

Wu, Y., Kihara, K., Takeda, Y., Sato, T., Akamatsu, M., \& Kitazaki, S. (2019). Effects of scheduled manual driving on drowsiness and response to take over request: a simulator study towards understanding drivers in automated driving. Accident Analysis \& Prevention, 124, 202-209. doi:10.1016/j.aap.2019.01.013

Zmud, J., Sener, I. N., \& Wagner, J. (2016). Consumer Acceptance and Travel Behavior Impacts of Automated Vehicles: Final Repor. 